\title{
Review
}

\section{Importance of NUDT15 Polymorphisms in Thiopurine Treatments}

\author{
Yoichi Tanaka * and Yoshiro Saito
}

check for

updates

Citation: Tanaka, Y.; Saito, Y. Importance of NUDT15

Polymorphisms in Thiopurine

Treatments. J. Pers. Med. 2021, 11, 778.

https://doi.org/10.3390/jpm11080778

Academic Editor: Su-Jun Lee

Received: 5 July 2021

Accepted: 8 August 2021

Published: 10 August 2021

Publisher's Note: MDPI stays neutral with regard to jurisdictional claims in published maps and institutional affiliations.

Copyright: (c) 2021 by the authors. Licensee MDPI, Basel, Switzerland. This article is an open access article distributed under the terms and conditions of the Creative Commons Attribution (CC BY) license (https:// creativecommons.org/licenses/by/ $4.0 /)$.
Division of Medicinal Safety Science, National Institute of Health Sciences, Kawasaki City 210-9501, Kanagawa, Japan; yoshiro@nihs.go.jp

* Correspondence: tanakayoichi@nihs.go.jp; Tel.: +81-44-270-6600

\begin{abstract}
Thiopurines, mercaptopurine, and azathioprine are used as immunosuppressants in the treatments of inflammatory bowel disease, rheumatoid arthritis, and organ transplantation and as chemotherapeutic drugs for the treatment of acute leukemia and chronic myeloid leukemia. This drug class sometimes causes severe adverse reactions, including bone marrow suppression and hair loss. Genetic polymorphisms of the metabolizing enzyme thiopurine S-methyltransferase have been used for predicting these reactions in Caucasians, but these allele frequencies are less frequently observed in Asian populations. Recently, nudix hydrolase 15 (NUDT15) polymorphisms have been shown to play an important role in thiopurine-induced adverse reactions in Asians. In this review, we summarize the NUDT15 studies, mainly in Asian countries, and their implementation in several countries.
\end{abstract}

Keywords: NUDT15; thiopurine; mercaptopurine; azathioprine; Asian; adverse effect; implementation

\section{Introduction}

Thiopurines, 6-mercaptopurine (6-MP) and azathioprine (AZA) are used as immunosuppressive and cytotoxic agents. AZA is used to maintain remission of inflammatory bowel disease (IBD) [1,2] and rheumatoid arthritis [3] and to inhibit immunological rejection of transplanted organs [4]. In hematological malignancies, 6-MP is used as maintenance therapy for 2-3 years [5]. Although thiopurine is the main component of these therapies, severe adverse effects of grade 3 or higher frequently occur. The typical adverse effects of thiopurines include myelosuppression, hair loss, hepatotoxicity, and pancreatitis.

To date, many studies have used a genetic approach to predict thiopurine-induced severe toxicities, especially myelosuppression. Thiopurine S-methyltransferase (TPMT) is an enzyme involved in thiopurine metabolism (Figure 1), and its genetic polymorphisms are known to be risk factors for intolerance to thiopurines [6]. The TPMT variants of c. $238 \mathrm{G}>\mathrm{C}, \mathrm{c} .460 \mathrm{G}>\mathrm{A}$, and c.719G $>\mathrm{A}$ induce protein instability and decrease the TPMT enzyme activity [7]. A low TPMT activity results in the accumulation of active metabolites, thiopurine nucleosides, in the cells, leading to cytotoxicity. The frequencies of variants with low TPMT activity differ among ethnic groups [6]. Caucasians and Africans have a high frequency of these polymorphisms, but Asians have lower frequencies of these TPMT nonfunctional variants; nonetheless, the frequencies of severe toxicities are similar among these races.

In addition to TPMT polymorphisms, nudix hydrolase 15 (NUDT15) c.415C > T (p.R139C) was associated with thiopurine intolerance in Asian populations, as reported in a previous genome-wide association study (GWAS) [8,9]. To date, NUDT15 is known to have 26 alleles, and NUDT15 *2 (p.V18_V19insGV and c.415C>T), *3 (c.415C>T), and *9 (c.50delGAGTCG) are recognized as loss-of-function variants (Table 1) [10,11]; however, other variants have been uncertain about the functional significance, referring to the Pharmacogene Variation Consortium (PharmVar, www.pharmvar.org). The NUDT15 enzyme dephosphorylates thiopurine triphosphate, which is the active metabolite incorporated into the DNA, to its monophosphate (Figure 1). The NUDT15 loss-of-function variants induce the increased 
levels of thiopurine triphosphate and thus higher incorporation of thioguanine nucleotides into the DNA and RNA. As a result, patients who inherited these variants experienced severe thiopurine-induced cytotoxicities, such as myelosuppression and alopecia. NUDT15 c. $415 \mathrm{C}>\mathrm{T}$ ( $\mathrm{p} . \mathrm{R} 139 \mathrm{C})$ is commonly detected in Asians but is rarely found in Caucasians and Africans, with allele frequencies of 0.12 and $<0.01$, respectively [6]. In this review, we aimed to provide a summary of the associations of NUDT15 alleles and their clinical significance, mainly in Asians, as well as their implementation in several countries.

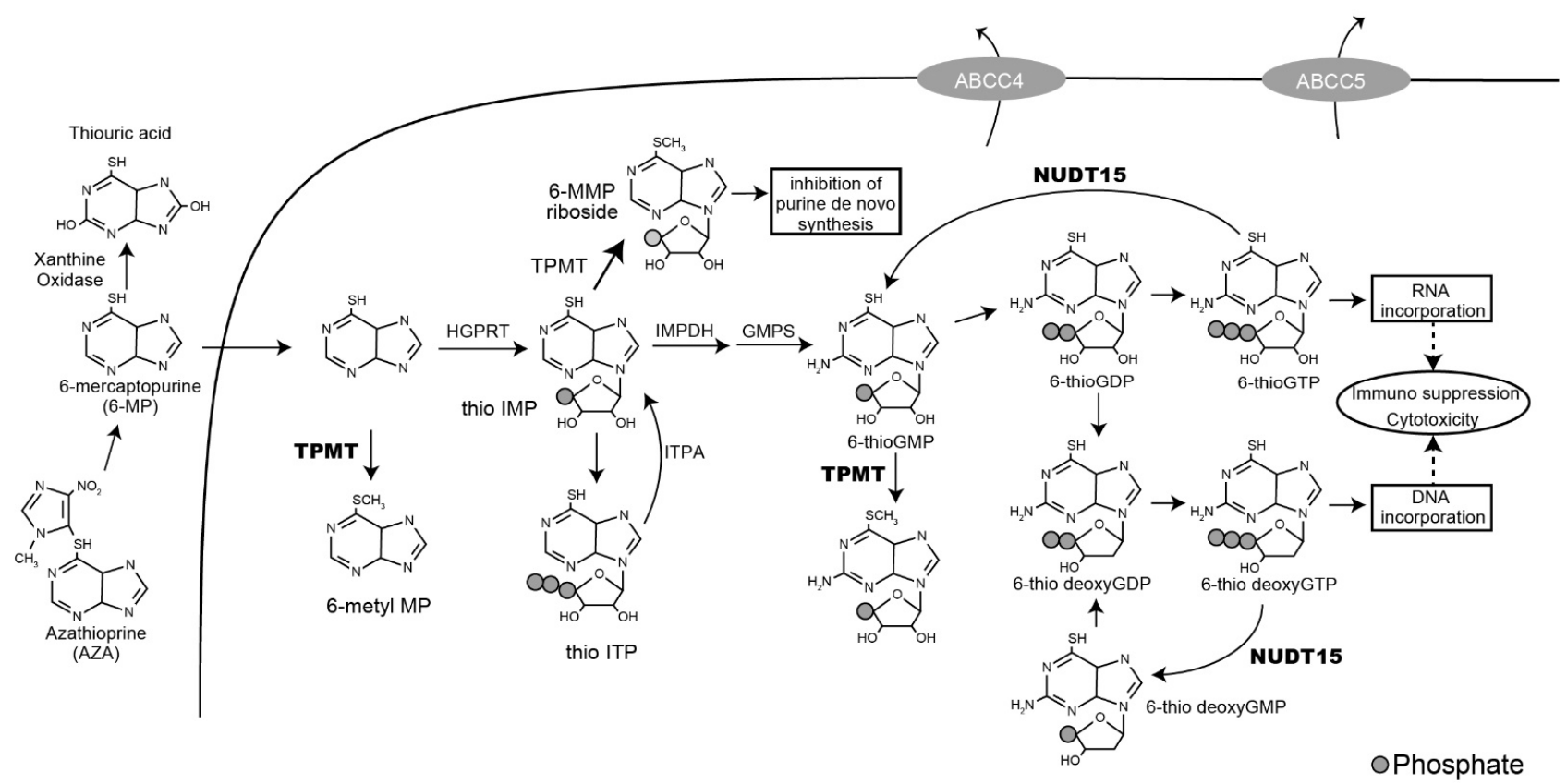

Figure 1. Thiopurine metabolism pathway. ABCC, ATP-binding cassette, subfamily C; GDP, guanosine diphosphate; GMP, guanosine monophosphate; GMPS, guanine monophosphate synthetase; GTP, guanosine triphosphate; HGPRT, hypoxanthine guanine phosphoribosyltransferase; IMP, inosine monophosphate; ITP, inosine triphosphate; IMPDH, inosine monophosphate dehydrogenase; NUDT15, nudix hydrolase 15; TPMT, thiopurine S-methyltransferase.

Table 1. Clinical impact of NUDT15 alleles in Asians.

\begin{tabular}{|c|c|c|c|c|c|c|}
\hline Allele & Variation & Amino Acid & $\begin{array}{c}\text { Estimated } \\
\text { Enzyme Activity }\end{array}$ & Disease & Clinical Impact & Reference \\
\hline *2 & $\begin{array}{l}\text { 55_56insGAGTCG } \\
415 \mathrm{C}>\mathrm{T}\end{array}$ & $\begin{array}{l}\text { V18_V19insGV } \\
\text { R139C }\end{array}$ & Low & $\begin{array}{l}\text { IBD } \\
\text { ALL }\end{array}$ & $\begin{array}{l}\text { AZA dose reduction } \\
\text { Leukopenia and hair loss } \\
\text { Leukopenia, 6-MP dose reduction }\end{array}$ & $\begin{array}{l}{[12]} \\
{[13]} \\
{[14,15]}\end{array}$ \\
\hline *3 & $415 \mathrm{C}>\mathrm{T}$ & $\mathrm{R} 139 \mathrm{C}$ & Low & $\begin{array}{l}\text { IBD } \\
\text { ALL }\end{array}$ & $\begin{array}{l}\text { AZA dose reduction } \\
\text { Leukopenia and hair loss } \\
\text { Leukopenia, dose reduction }\end{array}$ & $\begin{array}{l}{[12]} \\
{[13]} \\
{[10,14,16]}\end{array}$ \\
\hline$* 4$ & $416 \mathrm{G}>\mathrm{A}$ & $\mathrm{R} 139 \mathrm{H}$ & Intermediate & IBD & Leukopenia and hair loss (homo) & {$[13,17]$} \\
\hline$* 5$ & $52 \mathrm{G}>\mathrm{A}$ & V18I & Intermediate & $\begin{array}{l}\text { IBD } \\
\text { ALL }\end{array}$ & $\begin{array}{l}\text { Leukopenia } \\
\text { 6-MP dose reduction (homo) }\end{array}$ & $\begin{array}{l}{[13]} \\
{[14]}\end{array}$ \\
\hline${ }^{*} 6$ & 55_56insGAGTCG & V18_V19insGV & Intermediate & & & \\
\hline$* 7$ & $101 \mathrm{G}>\mathrm{C}$ & $\mathrm{R} 34 \mathrm{~T}$ & Low & ALL & Dose reduction & [11] \\
\hline$* 8$ & $103 \mathrm{~A}>\mathrm{G}$ & $\mathrm{K} 35 \mathrm{E}$ & Intermediate & ALL & Dose reduction (patient with $* 2 / * 8$ ) & [11] \\
\hline *9 & 50delGAGTCG & del17_18GV & Low & & & \\
\hline
\end{tabular}

IBD, inflammatory bowel disease; ALL, acute lymphoblastic leukemia; AZA, azathioprine; 6-MP, 6-mercaptopurine. 


\section{NUDT15 Variants and Toxicities in Thiopurine Metabolism}

\subsection{Thiopurine for Inflammatory Bowel Disease}

Thiopurine is administered for maintenance of remission and is used as a steroidsparing treatment for IBD. Approximately $25 \%$ of patients experience thiopurine-induced toxicities, especially myelosuppression [18]. The first study that reported the association between NUDT15 polymorphisms and 6-MP-induced toxicities was the GWAS conducted in Korean patients with Crohn's disease. Genotyping was performed in 978 patients using the immunochip array, while genotype imputation was carried out using the Asian reference panel. This study identified that the NUDT15 c.415C >T (p.R139C) variant was strongly associated with thiopurine-induced early leukopenia (white blood cell [WBC] count $\left.<3000 / \mathrm{mm}^{3}\right)$ (odds ratio [OR] $=35.6 ; \mathrm{P}$ [combined] $\left.=4.88 \times 10^{-94}\right)$ [8]. The association between the c.415C $>\mathrm{T}$ variant and with early leukopenia was replicated, and severe hair loss occurred within 8 weeks in 142 Japanese IBD patients with homozygous T variants treated with thiopurine [19]. The NUDT15 enzyme with 139C showed deficient activity and was significantly associated with thiopurine-induced leukopenia and alopecia. Some Asian study groups have validated the association between p.R139C or other variants of NUDT15 and thiopurine-induced toxicities in patients with IBD. The effect of multiple NUDT15 variants, c.415C > T, c.55_56insGAGTCG, and c.52G $>$ V, were evaluated to determine its association with leukopenia in 732 Chinese patients with IBD [12]. Results showed that these three variants were significantly associated with all grades of leukopenia, and a combination of these variants increased predictivity for leukopenia. By contrast, another study reported that NUDT15 functional variants in exon 1, c.55_56insGAGTCG a and c.52G>V, were not significantly associated with leukopenia and hair loss in Japanese patients with IBD [20].

The optimal therapeutic strategy using pharmacogenetic factors for the prediction of thiopurine-induced leukopenia and alopecia was retrospectively evaluated in 970 Japanese patients with IBD [13]. This study divided the NUDT15 diplotypes into different categories to estimate the enzyme activity (normal-normal, normal-intermediate, normal-low, intermediate-low, and low-low) and showed that the categorized diplotypes were significantly associated with leukopenia but not with severe alopecia. To determine the best method to predict severe leukopenia and alopecia, they performed GWAS and showed that NUDT15 c.415C $>$ T had the strongest association with severe leukopenia and alopecia $\left(p=1.3 \times 10^{-33}\right.$ and $4.3 \times 10^{-29}$, respectively), while previouslyreported variants of TPMT, $A B C C 4$, and RUNX1 were not associated with. NUDT15 c.416G >A (p.R139H, *4) was a rare variant, and Cys/His at codon 139 was a risk factor for acute severe leukopenia (within 8 weeks after thiopurine treatment) but not for alopecia. In a previous case report, patients with c.416AA experienced thiopurine-associated severe leukopenia and alopecia [17].

Thiopurine dose must be reduced in patients with NUDT15 variants to avoid thiopurineinduced severe toxicities, and therapeutic efficacy must be obtained at low doses. Some previous studies have shown an association between thiopurine dose and its efficacy in IBD patients with NUDT15 variants. Maeda et al. reported thiopurine-induced toxicities and efficacy in 30 patients with NUDT15 c.415 C/T [21]. These heterozygous patients were treated with $0.25 \mathrm{mg} / \mathrm{kg} /$ day of 6-MP, which was lower than the dose administered in c. $415 \mathrm{C} / \mathrm{C}$ patients $(0.48 \mathrm{mg} / \mathrm{kg})$. The non-relapse rates in ulcerative colitis treated with thiopurine monotherapy and surgery-free rates in Crohn's disease treated with combination therapy (thiopurines and antitumor necrosis factor- $\alpha$ agents) for maintenance of remission were not significantly different between c. $415 \mathrm{C} / \mathrm{C}$ patients and $\mathrm{C} / \mathrm{T}$ patients at 60 months $(p=0.339$ and $p=0.422$, respectively). Xu et al. showed that patients with heterozygous p.R139C were administered with significantly lower AZA dose compared with those with wild-type variants $(0.83 \mathrm{mg} / \mathrm{kg}$ vs. $1.04 \mathrm{mg} / \mathrm{kg})$, but the rate of clinical remission did not differ between these two patient groups [22]. Further studies are needed to determine the recommended dose for IBD patients with the NUDT15 variant; however, these findings might support the use of reduced thiopurine dose as initial treatment for patients with NUDT15 variants. 


\subsection{6-Mercaptopurine for Acute Lymphoblastic Leukemia}

6-MP is one of the primary components of multidrug therapy for acute lymphoblastic leukemia (ALL) [5]. In maintenance therapy, 6-MP is administered orally along with weekly methotrexate therapy for 2-3 years; a lower 6-MP dose intensity is associated with worse therapeutic outcomes [23].

In childhood ALL, the NUDT15 allele was initially associated with the administration of a 6-MP tolerance dose within the first 6 months in a multiracial GWAS of 657 children with ALL in the AALL03N1 study [9]. TPMT rs1142345 and NUDT15 c.415C > T (rs116855232) were significantly associated with the 6-MP dose in the initial 6 months of maintenance therapy. In this study, the NUDT15 variant allele was common among Asians and Hispanics, and this variant affected the 6-MP dose intensity with effective power similar to that of the TPMT variant. We evaluated the association between NUDT15 variant p.R139C and 6-MP intolerance in 92 Japanese children with ALL who received maintenance therapy [16]. Although the standard dose of 6-MP for Asians is $40-50 \mathrm{mg} / \mathrm{m}^{2}$, patients with NUDT15 R139C frequently experienced leukopenia (WBC count $<2000 / \mathrm{mm}^{3}$ ), and all of those with c.415T/T (p.139C/C) genotype developed leukopenia within 60 days. In this study, the 6-MP average doses of $40.7,29.3$, and $8.8 \mathrm{mg} / \mathrm{m}^{2}$ were used as maintenance therapy for patients with the $c .415 \mathrm{C} / \mathrm{C}, \mathrm{C} / \mathrm{T}$, and $\mathrm{T} / \mathrm{T}$ genotypes, respectively. These associations were validated in Thai [24,25], Taiwanese [26] and Korean populations [27]. In Chinese 60 ALL children whose 6-MP initial doses were adjusted based on TPMT genotypes, NUDT15 c.415C > T variant was also one of the significant risk factors for thiopurineinduced leukopenia (WBC $\leq 2000 / \mathrm{mm}^{3}$ ) [28]. Thus, NUDT15 c.415T/T is one of the major risk factors for severe leukopenia during early maintenance therapy, and 6-MP treatment is associated with a dramatic decrease in neutrophil counts. In 100 Thai children with ALL, those with mono- or bi-allelic variants of NUDT15 c.415C > T and c.55_56insGAGTCG showed lower neutrophil counts compared with those with wild-type variants, although the adjusted doses during the first 6 months of maintenance therapy for NUDT15 wild-type, mono-allelic, and bi-allelic variants were $50.0,36.6$, and $12.5 \mathrm{mg} / \mathrm{m}^{2} /$ day, respectively [29]. In 6-MP treatment, patients with bi-allelic variants experienced severe bone marrow suppression and required the discontinuation or reduction of significant doses. We recently evaluated the association between 6-MP intolerability and clinical characteristics in 37 children with ALL bearing NUDT15 bi-allelic variants in an Asian international collaboration retrospective study [14]. Among those with NUDT15 bi-allelic variants, more than $90 \%$ of the patients had a WBC count of $<2000 / \mathrm{mm}^{3}$ or a neutrophil count of $<1000 / \mathrm{mm}^{3}$. Interestingly, $86 \%$ of the patients had a neutrophil count of $<500 / \mathrm{mm}^{3}$. Our data showed that careful monitoring of neutrophil counts was of utmost importance, and the tolerable 6-MP dose was only $5.2 \mathrm{mg} / \mathrm{m}^{2}$ to maintain sufficient leukocyte range during maintenance therapy for patients with NUDT15 variants. We further demonstrated that adjusting the initial 6-MP dose is important to prevent the discontinuation of treatment and to allow the continuation of maintenance therapy, based on the NUDT15 genotype. In patients with NUDT15 bi-allelic variant, those who received an initial 6-MP dose of less than $10 \mathrm{mg} / \mathrm{m}^{2}$ experienced a shorter duration of therapy interruption than those who received more than $10 \mathrm{mg} / \mathrm{m}^{2}$ in the first 8 weeks (median range, 0 vs. 16 days) [14]. Based on the guideline of the Clinical Pharmacogenetics Implementation Consortium (CPIC), an initial 6-MP dose of $10 \mathrm{mg} / \mathrm{m}^{2}$ is recommended for patients with NUDT15 poor metabolizer diplotypes $(* 2 / 2, * 2 / * 3$, and $* 3 / * 3)$ (Table 2) [6]. Thus, our findings mentioned above verified this recommendation. To prevent the dramatic decline in neutrophil count, reducing the initial 6-MP dose to less than $10 \mathrm{mg} / \mathrm{m}^{2}$ is important, although a 6-MP dose adjustment is still recommended based on the patients' leucocyte count during the treatment.

NUDT15 alleles bearing variations other than those at codon 139 have uncertain functional significance for 6-MP tolerability in ALL patients because these variants are considered rare. In our study, eight patients inherited non-codon 139 variant alleles. The average 6-MP dose in patients with $* 2 / * 5, * 2 / * 7$, and $* 3 / * 5$ diplotypes was less than $10 \mathrm{mg} / \mathrm{m}^{2}$, while that in patients with ${ }^{*} 2 /{ }^{*} 6$ and ${ }^{*} 5 /{ }^{*} 5$ were tolerable for more than 
$10 \mathrm{mg} / \mathrm{m}^{2}$ [14]. A patient with $* 5 / 5$ required a reduction in the 6-MP dose because of the decreasing WBC counts, but a tolerable 6-MP dose of $17 \mathrm{mg} / \mathrm{m}^{2}$ was administered to maintain suitable blood cell counts. In another study conducted in Taiwanese children with ALL, the 6-MP dose for patients with ${ }^{*} 3 /{ }^{*} 6$ and ${ }^{*} 2 /{ }^{*} 7$ genotypes was less than $10 \mathrm{mg} / \mathrm{m}^{2}$ [15]. The frequencies of variants in exon 1 (such as c. 55_56insGAGTCG and c.52G $>V$ ) are extremely low, and the effects of these variants have not been revealed. To the best of our knowledge, the tolerable dose of 6-MP differs in various NUDT15 alleles.

Table 2. Recommended initial treatment and dose adjustment of thiopurine therapy for NUDT15 genotype based on the CPIC guidelines.

\begin{tabular}{|c|c|c|c|}
\hline $\begin{array}{c}\text { NUDT15 } \\
\text { Phenotype }\end{array}$ & Diplotypes & Mercaptopurine & Azathioprine \\
\hline Intermediate & $\begin{array}{c}* 1 / * 2 \text { and } \\
* 1 / * 3\end{array}$ & \multirow{2}{*}{$\begin{array}{l}\text { Start with reduced starting doses ( } 30-80 \% \text { of } \\
\text { normal dose) if normal starting doses is } \\
\geq 75 \mathrm{mg} / \mathrm{m}^{2} / \text { day or } \geq 1.5 \mathrm{mg} / \mathrm{kg} / \text { day and adjust } \\
\text { the dose of } 6 \text {-MP based on the degree of } \\
\text { myelosuppression and disease-specific guidelines. }\end{array}$} & $\begin{array}{l}\text { Start with reduced starting doses }(30-80 \% \text { of } \\
\text { normal dose) if normal starting dose is }\end{array}$ \\
\hline $\begin{array}{l}\text { Poss } \\
\text { interme } \\
\text { metabc }\end{array}$ & $\begin{array}{l}* 2 / * 4-* 9 \\
\text { and } \\
* 3 / * 4-* 9\end{array}$ & & $\begin{array}{l}2-3 \mathrm{mg} / \mathrm{kg} / \text { day and adjust the doses of AZA } \\
\text { based on the degree of myelosuppression } \\
\text { and disease-specific guidelines. }\end{array}$ \\
\hline $\begin{array}{c}\text { Poor } \\
\text { metabolizer }\end{array}$ & $\begin{array}{l}* 2 / * 2, * 2 / * 3, \\
\text { and } * 3 / * 3\end{array}$ & $\begin{array}{l}\text { Malignancy } \\
\text { An Initial dose of } 10 \mathrm{mg} / \mathrm{m}^{2} / \text { day should be used, } \\
\text { and the dose should be adjusted based on the } \\
\text { degree of myelosuppression and disease-specific } \\
\text { guidelines. } \\
\text { Non-malignancy } \\
\text { Consider alternative nonthiopurine } \\
\text { immunosuppressant therapy. }\end{array}$ & $\begin{array}{l}\text { Malignancy } \\
\text { Start with drastically reduced normal daily } \\
\text { doses of AZA (reduce daily dose 10-fold) and } \\
\text { then adjust the doses based on degree of } \\
\text { myelosuppression and disease-specific } \\
\text { guidelines. } \\
\text { Non-malignancy } \\
\text { Consider alternative nonthiopurine } \\
\text { immunosuppressant therapy. }\end{array}$ \\
\hline
\end{tabular}

\subsection{Other Diseases}

AZA has been used for the treatment of autoimmune and rheumatic diseases; however, only a few observational studies and case reports have examined patients with these diseases who developed AZA-induced toxicities associated with the NUDT15 variants.

In 149 Chinese patients with autoimmune hepatitis, the NUDT15 c.415T allele was significantly associated with leukopenia and neutropenia [30]. The maintenance dose of AZA for patients with the NUDT15 c.415T variant was lower than that of patients with the wild-type variant. The maintenance AZA doses for patients with the $C / C, C / T$, and $\mathrm{T} / \mathrm{T}$ diplotypes were $1.23,0.96$, and $0.2 \mathrm{mg} / \mathrm{kg} /$ day, respectively. Regarding rheumatic disease, NUDT15*3 genotype was associated with AZA-induced hematological toxicities, gastrointestinal effects, and hypochromia in 86 Chinese patients [31]. In AZA treatment for neuroimmunological disease, NUDT15 c.415T variant showed a higher frequency of leukopenia ( $\mathrm{OR}=6.5, p=0.003)$ and severe alopecia $(\mathrm{OR}=41.9, p=0.001)$ during treatment [32]. AZA-induced leukopenia was observed within 8 weeks of treatment in all patients with NUDT15 c.415T/T genotypes. This study population did not differ in AZA dose among those with NUDT15 genotypes, but the white blood cell counts were severely decreased in patients with a homozygous c.415T variant.

In dermatologic disease, NUDT15 c.415C > T (p.R139C) variant was associated with a severe decrease in neutrophil count $\left(<1500 / \mathrm{mm}^{3}\right)$ in 56 Chinese patients [33]. All three patients with NUDT15 c.415T/T had a neutrophil count of $<1500 / \mathrm{mm}^{3}$ within 8 weeks of treatment. Therefore, NUDT15 non-functional variants were also a risk factor for intolerability to thiopurine treatment in patients with autoimmune and rheumatic diseases.

In addition, AZA is used as an immunosuppressive therapy after organ transplantation. For this indication, only one case report was conducted to examine a kidney transplantation patient with a homozygous NUDT15 p.139C variant [34]. This patient developed fever, leukopenia, and alopecia within 4 days of AZA initiation and was treated with mycophenolate mofetil. 


\section{Dose Adjustment Based on NUDT15 Alleles}

The CPIC guideline recommends thiopurine dosing based on the NUDT15 diplotypes (Table 2). For malignant patients with NUDT15 poor metabolizer diplotypes $\left({ }^{*} 2 /{ }^{*} 2,{ }^{*} 2 /{ }^{*} 3\right.$, and $* 3 / 3$ ), thiopurine drugs start in drastically reduced daily dose, i.e., $10 \mathrm{mg} / \mathrm{m}^{2}$ of 6-MP, to minimize toxicities. For patients with non-malignant conditions, the guideline recommends the use of an alternative non-thiopurine immunosuppressant therapy for NUDT15 poor metabolizers.

Chang et al. reported the efficacy of adjusting the AZA dose based on the results of preemptive genotyping for common variants of NUDT15 (rs116855232; p.R139C), FTO (rs79206939), and TPMT (rs1800460, rs1800462 and rs1142345; p.A154T, p.A80P, p.Y240C or Y240S, respectively) compared with non-genotyping group in 164 Korean IBD patients [35]. The heterozygotes of the genotyped patients received AZA $50 \mathrm{mg}$ or 6-MP $25 \mathrm{mg}$ daily, while the homozygotes were recommended to take alternative drugs. The genotyping group showed a lower frequency of myelosuppression (WBC count of $<3000 / \mathrm{mm}^{3}$, platelet count of $<1 \times 10^{6} / \mathrm{mm}^{3}$, and hemoglobin level of $<10 \mathrm{~g} / \mathrm{dL}$, which decreased to $>2 \mathrm{~g} / \mathrm{dL}$ ) than the non-genotyping group (17\% vs. $36 \%, p=0.005)$. Furthermore, fewer thiopurine treatment discontinuations or dose reductions were required in the genotyping group. However, to the best of our knowledge, the efficacy of 6-MP initial dose adjustment based on the NUDT15 variants to achieve favorable therapeutic outcomes has not been reported in any disease.

\section{NUDT15 Genotype Information in Drug Labels}

Based on the above sections, data on the NUDT15 genotype are useful for ensuring the safety of patients administered thiopurines, in addition to TPMT genotypes. In this context, the drug labels of AZA and 6-MP in some countries include NUDT15 genotype information (Table 3). The labels of US FDA describe the consideration of NUDT15 genotyping in patients experiencing severe myelosuppression. If patients with homozygous deficient alleles of either TPMT or NUDT15, alternative therapies (AZA) or dosage reduction (6-MP) should be considered. For patients with heterozygous deficient alleles of either TPMT or NUDT15, the drug labels indicate the recommendation for dosage reduction (AZA) or reduced dosage based on tolerability (6-MP). UK MHRA drug labels indicate an increased risk of toxicity among patients with inherited mutated NUDT15 gene, and reduced dosage is generally required for these patients. Genotypic testing of NUDT15 variants may be considered before initiating AZA and 6-MP therapies. A similar description was found in the Canadian and Australian drug labels of AZA. In addition, the Australian drug labels stipulate that Asians have a particular risk of NUDT15 deficiency. Japanese drug labels specify the frequent occurrence of leukopenia among patients with the NUDT15 p.R139C genotype, referring to published papers. In the AZA label, caution should be paid, such as considering the use of other drugs in patients with the NUDT15 p.R139C genotype. Interestingly, the Singapore and Malaysia drug labels did not specify any warnings for patients with NUDT15 genotypes. Because Asians have higher frequencies of the NUDT15 p.R139C allele than European and African populations, the drug labels may be revised in the future. 
Table 3. Description of NUDT15 polymorphisms in the drug labels of countries.

\begin{tabular}{|c|c|c|c|}
\hline \multirow{2}{*}{ Country } & \multirow{2}{*}{$\begin{array}{c}\text { Description of } \\
\text { TPMT } \\
\text { Polymorphisms }\end{array}$} & \multicolumn{2}{|c|}{ Description of NUDT15 Polymorphisms in the Drug Labels } \\
\hline & & Azathioprine (AZA) * & 6-Mercaptopurine (6-MP) \\
\hline US & $\begin{array}{l}\text { AZA: } \bigcirc \\
\text { 6-MP: } \bigcirc\end{array}$ & $\begin{array}{l}\text { Dosage and Administrations: } \\
\text { Patients with TPMT and/or NUDT15 Deficiency: } \\
\text { Consider testing for TPMT and NUDT15 deficiency in } \\
\text { patients who experience severe bone marrow toxicities. } \\
\text { Homozygous deficiency in either TPMT or NUDT15: } \\
\text { Because of the risk of increased toxicity, consider } \\
\text { alternative therapies for patients who are known to have } \\
\text { TPMT or NUDT15 deficiency. } \\
\text { Heterozygous deficiency in TPMT and/or NUDT15: } \\
\text { Because of the risk of increased toxicity, dosage reduction } \\
\text { is recommended in patients known to have heterozygous } \\
\text { deficiency of TPMT or NUDT15. Patients who are } \\
\text { heterozygous for both TPMT and NUDT15 deficiency } \\
\text { may require more substantial dosage reductions. } \\
\text { (Also described in the Warnings section and Precaution } \\
\text { section) }\end{array}$ & $\begin{array}{l}\text { Dosage and Administrations: } \\
\text { Dosage Modifications in Patients with TPMT and NUDT15 Deficiency: } \\
\text { Consider testing for TPMT and NUDT15 deficiency in patients who } \\
\text { experience severe myelosuppression or repeated episodes of } \\
\text { myelosuppression. } \\
\text { Homozygous Deficiency in either TPMT or NUDT15: } \\
\text { Patients with homozygous deficiency of either enzyme typically } \\
\text { require } 10 \% \text { or less of the recommended dosage. Reduce the } \\
\text { recommended starting dosage in patients who are known to have } \\
\text { homozygous TPMT or NUDT15 deficiency. } \\
\text { Heterozygous Deficiency in TPMT and/or NUDT15: } \\
\text { Reduce the dose based on tolerability. Most patients with } \\
\text { heterozygous TPMT or NUDT15 deficiency tolerate the } \\
\text { recommended dosage, but some require a dose reduction based on } \\
\text { adverse reactions. Patients who are heterozygous for both TPMT } \\
\text { and NUDT15 may require more substantial dose reductions. } \\
\text { (Also described in the Warnings and Precautions section) }\end{array}$ \\
\hline UK & $\begin{array}{l}\text { AZA: } \bigcirc \\
\text { 6-MP: } \bigcirc\end{array}$ & $\begin{array}{l}\text { Posology and method of administration: } \\
\text { Patients with NUDT15 variant: } \\
\text { Patients with inherited mutated NUDT15 gene are at } \\
\text { increased risk for severe AZA toxicity. These patients } \\
\text { generally require dose reduction particularly those with } \\
\text { homozygous NUDT15 variants. Genotypic testing of } \\
\text { NUDT15 variants may be considered before initiating } \\
\text { AZA therapy. In any case, close monitoring of blood } \\
\text { counts is necessary. } \\
\text { (Also described in the Special Warning and Precautions } \\
\text { section) }\end{array}$ & $\begin{array}{l}\text { Posology and method of administration: } \\
\text { Patients with NUDT15 variant: } \\
\text { Patients with inherited mutated NUDT15 gene are at increased risk } \\
\text { for severe 6-MP toxicity. These patients generally require dose } \\
\text { reduction; particularly those with homozygous NUDT15 variants. } \\
\text { Genotypic testing of NUDT15 variants may be considered before } \\
\text { initiating 6-MP therapy. In any case, close monitoring of blood } \\
\text { counts is necessary. } \\
\text { (Also described in the Special Warning and Precautions section) }\end{array}$ \\
\hline
\end{tabular}

Dosage and Administrations:

Patients with NUDT15 variant

Patients with inherited mutated NUDT15 gene are at

increased risk for severe 6-MP toxicity. These patients

AZA: $\bigcirc \quad$ generally require dose reduction, particularly those with

6-MP: $\bigcirc \quad$ hUDT15 variants may be considered before initiating

Not mentioned.

6-MP therapy. In any case, close monitoring of blood

counts is necessary.

(Also described in the Warning and Precautions section and Pharmacokinetics section)

\section{Special Warnings and Precautions for Use:}

NUDT15 Testing

Patients with inherited mutated NUDT15 gene are at increased risk for severe thiopurine toxicity, such as early leukopenia and alopecia, from conventional doses of thiopurine therapy and generally require substantial dose reduction. Patients of Asian ethnicity are

AZA: $\bigcirc$ particularly at risk, due to the increased frequency of the

6-MP: $\bigcirc \quad$ mutation in this population. The optimal starting dose for heterozygous or homozygous deficient patients h
not been established. Close monitoring of blood cell count is necessary.

Genotypic and phenotypic testing of NUDT15 variants

should be considered before initiating thiopurine therapy in all patients (including pediatric patients) to reduce the risk of thiopurine-related severe leukocytopenia and alopecia, especially in Asian populations.

\section{Important precautions:}

It has been reported that patients with NUDT15
Arg139Cys genetic polymorphisms are more likely to Japan $\quad$ 6-MP: $X \quad \begin{aligned} & \text { develop leukopenia after drug administration. Therefore, } \\ & \text { caution should be exercised, such as considering the use }\end{aligned}$ of other drugs.

(Also described in the Other Precautions section)

Not mentioned.

\section{Other Precautions:}

It has been reported that patients with NUDT15 Arg139Cys genetic polymorphisms are more likely to develop leukopenia after drug administration.

\begin{tabular}{cccc}
\hline \multirow{2}{*}{ Singapore } & AZA: $\bigcirc$ & Not mentioned & Not mentioned \\
\hline Malaysia & AZA: $\bigcirc$ & Not mentioned & Label was not available. \\
\hline
\end{tabular}

* IMURAN labels. AZP, azathioprine; 6-MP, 6-mercaptopurine. 


\section{Conclusions}

NUDT15 is a major predictive genetic marker of thiopurine tolerance in Asians. NUDT15 c.415C > T (p.R139C) is a common variant and induces severe myelosuppression and hair loss; thus, patients with this variant require a dose reduction. However, the clinical significance of other low-frequency variants has not yet been fully evaluated. The functional effects are likely to vary depending on the NUDT15 alleles, and determining the NUDT15 diplotype could help in the development of a thiopurine therapy that is tailored to the needs of each patient. Further studies are needed to evaluate the clinical usefulness of determining the initial thiopurine dose based on preemptive NUDT15 genotyping over the next decade.

Author Contributions: Conceptualization, writing and review, and editing: Y.T. and Y.S. All authors have read and agreed to the published version of the manuscript.

Funding: This research was partly funded by AMED (grant number: JP20kk0305014) and by a grant from the Ministry of Health, Labour and Welfare of Japan (grant number: 20KC2010).

Institutional Review Board Statement: Not applicable.

Informed Consent Statement: Not applicable.

Data Availability Statement: Not applicable.

Acknowledgments: The authors thank Chie Sudo for providing secretarial assistance.

Conflicts of Interest: The authors declare no conflict of interest.

\section{References}

1. Chande, N.; Patton, P.H.; Tsoulis, D.J.; Thomas, B.S.; Macdonald, J.K. Azathioprine or 6-mercaptopurine for maintenance of remission in Crohn's disease. Cochrane Database Syst. Rev. 2015, CD000067. [CrossRef]

2. Timmer, A.; Patton, P.H.; Chande, N.; Mcdonald, J.W.; Macdonald, J.K. Azathioprine and 6-mercaptopurine for maintenance of remission in ulcerative colitis. Cochrane Database Syst. Rev. 2016, 2016, CD000478. [CrossRef] [PubMed]

3. Broen, J.C.A.; van Laar, J.M. Mycophenolate mofetil, azathioprine and tacrolimus: Mechanisms in rheumatology. Nat. Rev. Rheumatol. 2020, 16, 167-178. [CrossRef]

4. Taylor, A.L.; Watson, C.J.E.; Bradley, J.A. Immunosuppressive agents in solid organ transplantation: Mechanisms of action and therapeutic efficacy. Crit. Rev. Oncol. Hematol. 2005, 56, 23-46. [CrossRef]

5. Kato, M.; Manabe, A. Treatment and biology of pediatric acute lymphoblastic leukemia. Pediatr. Int. 2018, 60, 4-12. [CrossRef] [PubMed]

6. Relling, M.V.; Schwab, M.; Whirl-Carrillo, M.; Suarez-Kurtz, G.; Pui, C.-H.; Stein, C.M.; Moyer, A.M.; Evans, W.E.; Klein, T.E.; Antillon-Klussmann, F.G.; et al. Clinical pharmacogenetics implementation consortium guideline for thiopurine dosing based on TPMT and NUDT 15 genotypes: 2018 update. Clin. Pharmacol. Ther. 2019, 105, 1095-1105. [CrossRef] [PubMed]

7. Evans, W.E. Pharmacogenetics of thiopurine S-methyltransferase and thiopurine therapy. Ther. Drug Monit. 2004, 26, 186-191. [CrossRef] [PubMed]

8. Yang, S.-K.; Hong, M.; Baek, J.; Choi, H.; Zhao, W.; Jung, Y.; Haritunians, T.; Duk Ye, B.; Kim, K.-J.; Hyoung Park, S.; et al. A common missense variant in NUDT15 confers susceptibility to thiopurine-induced leukopenia. Nat. Genet. 2014, 46, 1017-1020. [CrossRef]

9. Yang, J.J.; Landier, W.; Yang, W.; Liu, C.; Hageman, L.; Cheng, C.; Pei, D.; Chen, Y.; Crews, K.R.; Kornegay, N.; et al. Inherited NUDT15 variant is a genetic determinant of mercaptopurine intolerance in children with acute lymphoblastic leukemia. J. Clin. Oncol. 2015, 33, 1235-1242. [CrossRef] [PubMed]

10. Moriyama, T.; Nishii, R.; Perez-Andreu, V.; Yang, W.; Klussmann, F.A.; Zhao, X.; Lin, T.N.; Hoshitsuki, K.; Nersting, J.; Kihira, K.; et al. NUDT15 polymorphisms alter thiopurine metabolism and hematopoietic toxicity. Nat. Genet. 2016, 48, 367-373. [CrossRef]

11. Moriyama, T.; Yang, Y.L.; Nishii, R.; Ariffin, H.; Liu, C.; Lin, T.N.; Yang, W.; Lin, D.T.; Yu, C.H.; Kham, S.; et al. Novel variants in NUDT15 and thiopurine intolerance in children with acute lymphoblastic leukemia from diverse ancestry. Blood 2017, 130, 1209-1212. [CrossRef]

12. Chao, K.; Wang, X.; Cao, Q.; Qian, J.; Wu, K.; Zhu, X.; Yang, H.; Liang, J.; Lin, L.; Huang, Z.; et al. Combined detection of NUDT15 variants could highly predict thiopurine-induced leukopenia in Chinese patients with inflammatory bowel disease. Inflamm. Bowel Dis. 2017, 23, 1592-1599. [CrossRef] [PubMed] 
13. Kakuta, Y.; Kawai, Y.; Okamoto, D.; Takagawa, T.; Ikeya, K.; Sakuraba, H.; Nishida, A.; Nakagawa, S.; Miura, M.; Toyonaga, T.; et al. NUDT15 codon 139 is the best pharmacogenetic marker for predicting thiopurine-induced severe adverse events in Japanese patients with inflammatory bowel disease: A multicenter study. J. Gastroenterol. 2018, 53, 1065-1078. [CrossRef]

14. Tanaka, Y.; Yeoh, A.E.J.; Moriyama, T.; Li, C.-K.; Kudo, K.; Arakawa, Y.; Buaboonnam, J.; Zhang, H.; Liu, H.-C.; Ariffin, H.; et al. An international retrospective study for tolerability of 6-mercaptopurine on NUDT15 bi-allelic variants in children with acute lymphoblastic leukemia. Haematologica 2021. [CrossRef]

15. Yu, C.H.; Chang, Y.H.; Wang, D.S.; Jou, S.T.; Lin, C.Y.; Lin, K.H.; Lu, M.Y.; Raghav, L.; Chang, H.H.; Wu, K.H.; et al. Determination of NUDT15 variants by targeted sequencing can identify compound heterozygosity in pediatric acute lymphoblastic leukemia patients. Sci. Rep. 2020, 10, 14400. [CrossRef] [PubMed]

16. Tanaka, Y.; Kato, M.; Hasegawa, D.; Urayama, K.Y.; Nakadate, H.; Kondoh, K.; Nakamura, K.; Koh, K.; Komiyama, T.; Manabe, A. Susceptibility to 6-MP toxicity conferred by a NUDT15 variant in Japanese children with acute lymphoblastic leukaemia. Br. J. Haematol. 2015, 171, 109-115. [CrossRef] [PubMed]

17. Tomiyoshi, K.; Sato, H.; Tominaga, K.; Kawata, Y.; Okamoto, D.; Kakuta, Y.; Yokoyama, J.; Terai, S. Rare genotype of his/his in NUDT15 codon 139 and thiopurine-associated adverse events in a case of ulcerative colitis. Intern. Med. 2020, 59, 1611-1613. [CrossRef]

18. Chang, J.Y.; Cheon, J.H. Thiopurine therapy in patients with inflammatory bowel disease: A focus on metabolism and pharmacogenetics. Dig. Dis. Sci. 2019, 64, 2395-2403. [CrossRef]

19. Kakuta, Y.; Naito, T.; Onodera, M.; Kuroha, M.; Kimura, T.; Shiga, H.; Endo, K.; Negoro, K.; Kinouchi, Y.; Shimosegawa, T. NUDT15 R139C causes thiopurine-induced early severe hair loss and leukopenia in Japanese patients with IBD. Pharm. J. 2016, 16, 280-285. [CrossRef]

20. Sato, T.; Takagawa, T.; Kakuta, Y.; Nishio, A.; Kawai, M.; Kamikozuru, K.; Yokoyama, Y.; Kita, Y.; Miyazaki, T.; Iimuro, M.; et al. NUDT15, FTO, and RUNX1 genetic variants and thiopurine intolerance among Japanese patients with inflammatory bowel diseases. Intest. Res. 2017, 15, 328-337. [CrossRef]

21. Maeda, T.; Sakuraba, H.; Hiraga, H.; Yoshida, S.; Kakuta, Y.; Kikuchi, H.; Kawaguchi, S.; Hasui, K.; Tatsuta, T.; Chinda, D.; et al. Long-term efficacy and tolerability of dose-adjusted thiopurine treatment in maintaining remission in inflammatory bowel disease patients with NUDT15 heterozygosity. Intest. Res. 2021. [CrossRef] [PubMed]

22. Xu, Y.; Qiao, Y.Q.; Li, H.Y.; Zhou, M.; Cai, C.W.; Shen, J.; Ran, Z.H. NUDT15 genotyping during azathioprine treatment in patients with inflammatory bowel disease: Implications for a dose-optimization strategy. Gastroenterol. Rep. 2020, 8, 437-444. [CrossRef] [PubMed]

23. Relling, M.V.; Hancock, M.L.; Boyett, J.M.; Pui, C.H.; Evans, W.E. Prognostic importance of 6-mercaptopurine dose intensity in acute lymphoblastic leukemia. Blood 1999, 93, 2817-2823. [CrossRef]

24. Chiengthong, K.; Ittiwut, C.; Muensri, S.; Sophonphan, J.; Sosothikul, D.; Seksan, P.; Suppipat, K.; Suphapeetiporn, K.; Shotelersuk, $\mathrm{V}$. NUDT15 c.415C $>\mathrm{T}$ increases risk of 6-mercaptopurine induced myelosuppression during maintenance therapy in children with acute lymphoblastic leukemia. Haematologica 2016, 101, e24-e26. [CrossRef]

25. Buaboonnam, J.; Sripatanatadasakul, P.; Treesucon, A.; Glomglao, W.; Siraprapapat, P.; Narkbunnam, N.; Vathana, N.; Takpradit, C.; Phuakpet, K.; Pongtanakul, B.; et al. Effect of NUDT15 on incidence of neutropenia in children with acute lymphoblastic leukemia. Pediatr. Int. 2019, 61, 754-758. [CrossRef]

26. Liang, D.C.; Yang, C.P.; Liu, H.C.; Jaing, T.H.; Chen, S.H.; Hung, I.J.; Yeh, T.C.; Lin, T.H.; Lai, C.L.; Lai, C.Y.; et al. NUDT15 gene polymorphism related to mercaptopurine intolerance in Taiwan Chinese children with acute lymphoblastic leukemia. Pharm. J. 2016, 16, 536-539. [CrossRef] [PubMed]

27. Choi, R.; Sohn, I.; Kim, M.J.; Woo, H.I.; Lee, J.W.; Ma, Y.; Yi, E.S.; Koo, H.H.; Lee, S.Y. Pathway genes and metabolites in thiopurine therapy in Korean children with acute lymphoblastic leukaemia. Br. J. Clin. Pharmacol. 2019, 85, 1585-1597. [CrossRef]

28. Zhou, Y.; Wang, L.; Zhai, X.Y.; Wen, L.; Tang, F.; Yang, F.; Liu, X.T.; Dong, L.; Zhi, L.J.; Shi, H.Y.; et al. Precision therapy of 6-mercaptopurine in Chinese children with acute lymphoblastic leukaemia. Br. J. Clin. Pharmacol. 2020, 86, 1519-1527. [CrossRef]

29. Puangpetch, A.; Tiyasirichokchai, R.; Pakakasama, S.; Wiwattanakul, S.; Anurathapan, U.; Hongeng, S.; Sukasem, C. NUDT15 genetic variants are related to thiopurine-induced neutropenia in Thai children with acute lymphoblastic leukemia. Pharmacogenomics 2020, 21, 403-410. [CrossRef]

30. Fan, X.; Yin, D.; Men, R.; Xu, H.; Yang, L. NUDT15 polymorphism confer increased susceptibility to thiopurine-induced leukopenia in patients with autoimmune hepatitis and related cirrhosis. Front. Pharmacol. 2019, 10, 346. [CrossRef]

31. Yang, J.; Wang, P.; Qin, Z.; Jia, M.; Zhang, C.; Tian, X.; Zheng, Y.; Zhang, A.; Zhang, X.; Liu, S. NUDT15 and TPMT genetic polymorphisms are related to azathioprine intolerance in Chinese patients with rheumatic diseases. Genet. Test. Mol. Biomark. 2019, 23, 751-757. [CrossRef] [PubMed]

32. Kim, S.Y.; Shin, J.H.; Park, J.S.; Kang, S.Y.; Nam, T.S.; Kim, J.K.; Park, K.J.; Huh, S.Y.; Oh, J.S.; Kang, B.; et al. NUDT15 p.R139C variant is common and strongly associated with azathioprine-induced early leukopenia and severe alopecia in Korean patients with various neurological diseases. J. Neurol. Sci. 2017, 378, 64-68. [CrossRef] [PubMed]

33. Shih, Y.C.; Zou, Y.R.; Wang, B.; Zheng, J.; Pan, M. Azathioprine-induced myelosuppression in two pemphigus vulgaris patients with homozygous polymorphism of NUDT15. J. Dermatol. 2019, 46, e59-e61. [CrossRef] [PubMed] 
34. Saida, K.; Kamei, K.; Ogura, M.; Matsumura, S.; Kano, Y.; Sato, M.; Andoh, A.; Ishikura, K. Azathioprine-induced agranulocytosis and severe alopecia after kidney transplantation associated with a NUDT15 polymorphism: A case report. Transplant. Proc. 2018, 50, 3925-3927. [CrossRef]

35. Chang, J.Y.; Park, S.J.; Jung, E.S.; Jung, S.A.; Moon, C.M.; Chun, J.; Park, J.J.; Kim, E.S.; Park, Y.; Kim, T.I.; et al. Genotypebased treatment with thiopurine reduces incidence of myelosuppression in patients with inflammatory bowel diseases. Clin. Gastroenterol. Hepatol. 2020, 18, 2010-2018. [CrossRef] 